\title{
Subacute Wernicke's encephalopathy due to gastric syphilis
}

\author{
ALISON C REID AND P O BEHAN \\ From the University Department of Neurology, Institute of Neurological Sciences, Southern General \\ Hospital, Glasgow
}

SUMMARY In a patient who presented with subacute Wernicke's encephalopathy the underlying gastric lesion was found to be due to syphilis.

\section{Introduction}

Syphilis of the stomach was first described by Andral $^{1}$ in 1834, and in the following decades several case reports were published. By the early twentieth century, however, it had become very uncommon. Morton $^{2}$ reported that he found 314 cases of generalised syphilis in a necropsy series of 4880 , but only one case had syphilis of the stomach. The incidence has declined further and there have been only occasional reports up to $1960,{ }^{3-6}$ and even fewer over the past 20 years. ${ }^{78}$ Nevertheless, the condition still exists, as shown by this report of a patient who presented with subacute Wernicke's encephalopathy associated with anorexia and vomiting due to syphilitic inflammation and constriction of the stomach.

\section{Case report}

\section{CLINICAL HISTORY}

In July 1979 a 60 -year-old man presented with a sixmonth history of double vision, tremor affecting the arms and legs, confusion, and deterioration in recent memory. He also complained of anorexia, nausea, frequent episodes of vomiting, and loss of $18 \mathrm{~kg}$ in weight. He drank no alcohol. He was a thin illlooking man; his pulse rate was 100 beats/minute; his blood pressure was $160 / 70 \mathrm{~mm} \mathrm{Hg}$, and he had a short diastolic murmur of aortic incompetence. The chest was clear and the abdomen was lean and not tender. He had poor memory for recent events and a

Address for reprints: $\operatorname{Dr}$ A C Reid, University Department of Neurology, Institute of Neurological Sciences, Southern General Hospital, Glasgow G51 4TF

Accepted for publication 14 February 1981 coarse tremor of the hands and legs. There was no nystagmus and extraocular movements were full, but he could not walk in a tandem fashion.

\section{DIAGNOSTIC AND LABORATORY TESTS}

Chest radiographs showed an unfolded aorta and enlarged heart; an electrocardiograph was diagnostic of left bundle branch block. An electroencephalograph showed a mild excess of slow-wave activity; slight cerebral atrophy was seen on the computerised axial tomograph. All reaginic and specific blood tests for syphilis gave positive results (table). The cerebrospinal fluid cell count, protein, and glucose values were within normal limits. The Lange curve was normal, and serological test results for syphilis were negative.

A barium-meal examination showed a grossly abnormal mucosal pattern on the posterior wall of the upper body of the stomach and absent peristalsis (fig 1). The appearances were consistent with linitis plastica. Endoscopy showed a narrow area extending from 50 to $60 \mathrm{~cm}$, which was inflamed but not ulcerated; the appearance was strongly suggestive of a constricting carcinoma. The histology report read: "Sections of multiple gastric biopsies consist of pyloric mucosa and one fragment from the oesophagogastric junction. There are severe changes of active chronic gastritis with slight glandular atrophy and a few foci of intestinal metaplasia. There is no evidence of malignancy."

\section{TREATMENT}

The patient was treated with a two-week course of intramuscular procaine penicillin $1 \mathrm{~g}$ daily, vitamin supplements, and pizotifen, a drug known for its appetite-stimulating properties; he was then discharged home. 


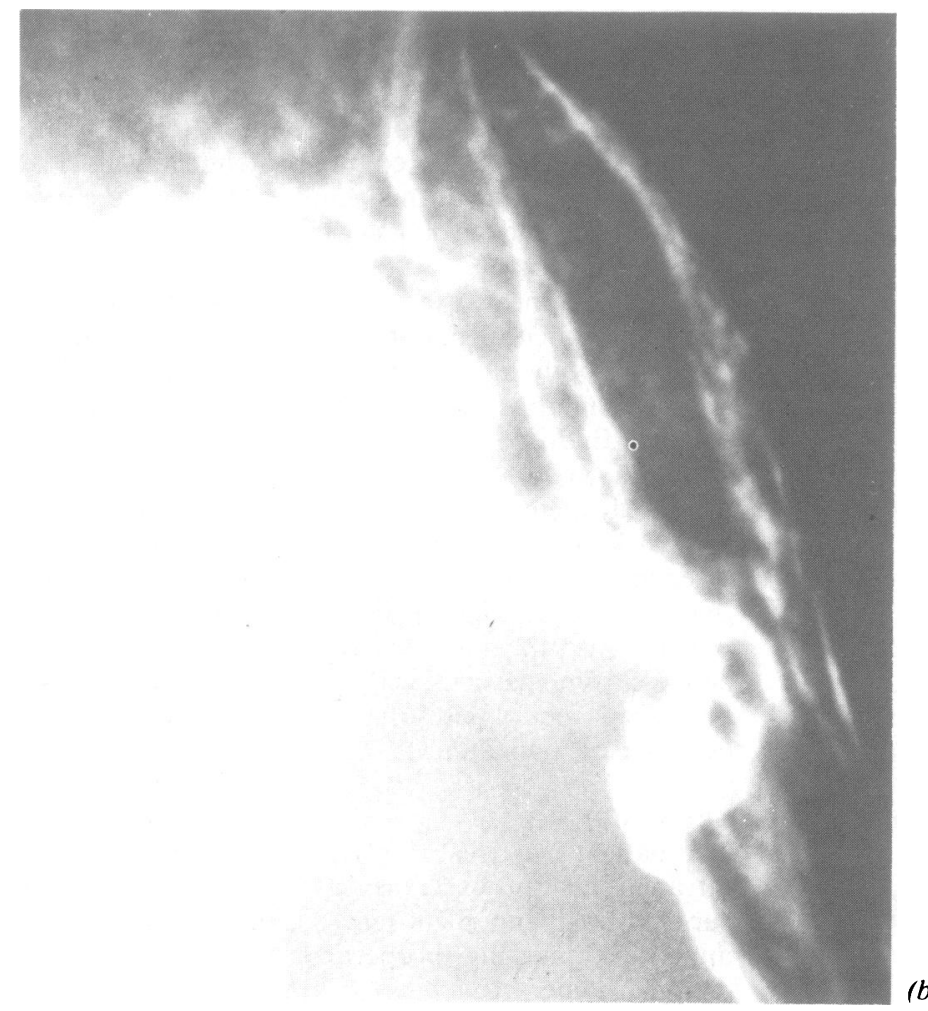

FIGURE Radiographs of barium-meal examination, July 1971. (a) Anteroposterior view of posterior wall of fundus of stomach showing grossly abnormal mucosal pattern. (b) Lateral projection showing infiltrating lesion in posterior wall of fundus. 


\section{FOLLOW UP}

When readmitted in January 1980 he had no neurological symptoms or signs. He was eating small regular meals and had put on weight. Serological tests for syphilis were repeated (table). A further barium-meal examination and endoscopy showed a dramatic improvement in the macroscopic appearances, although gastric biopsies indicated that there had not been total resolution of the chronic inflammatory infiltrate. When the patient was reviewed again in January 1981 he was still well and was eating normally.

TABLE Serological test results

\begin{tabular}{lll}
\hline & \multicolumn{2}{l}{ Results in: } \\
\cline { 2 - 3 } Serological tests & July 1979 & Jan 1980 \\
\hline WR & + & Weakly + \\
VDRL & + (titre not given $)$ & $+($ titre not given $)$ \\
RPCFT & + & - \\
TPHA & + (titre $1 / 160)$ & $+($ titre $1 / 80)$ \\
FTA-ABS & + & Weakly + \\
\hline
\end{tabular}

$+=$ Positive; - = negative

$\mathbf{W R}=$ Wassermann reaction; $\mathrm{VDRL}=$ Venereal Disease Research Laboratory (test); RPCFT $=$ Reiter protein complement-fixation test; TPHA = Treponema pallidum haemagglutination assay; FTAABS $=$ fluorescent treponemal antibody-absorption (test).

\section{Discussion}

This patient complied with the criteria essential for the clinical diagnosis of gastric syphilis 9 : untreated tertiary syphilis; a demonstrable radiological and endoscopic defect; presence of gastric symptoms; and clinical and radiological improvement after specific therapy. The presence of aortic incc.npetence was almost certainly due to syphilitic cardiovascular disease. The clinical presentation strongly suggested subacute Wernicke's encephalopathy secondary to prolonged anorexia and intermittent vomiting. ${ }^{10}$ Examination of the CSF gave no indication that syphilitic involvement of the nervous system underlay the neurological presentation.

Gastric syphilis may present radiologically ${ }^{1}$ as concentric tubular constriction of the prepyloric or antral region, as constriction in the middle of the stomach resulting in an hour-glass deformity, or as diffuse involvement of the stomach wall giving a linitis plastica type of appearance. The latter was present in this patient and was indistinguishable macroscopically from infiltrating carcinoma.

In retrospect the histological findings in this case were quite compatible with the diagnosis of gastric syphilis, since the histological appearances in this condition are non-specific and there is no pathognomonic feature. The inflammatory cell infiltrate occurs predominantly in the submucosa with striking proliferative endarteritis and panphlebitis. Nodular gumma-like lesions may occur, but usually the involvement is diffuse producing swelling and thickening of the stomach wall.

This case illustrates the fact that even in the $1980 \mathrm{~s}$ syphilis still deserves respect as the "great imitator."

\section{References}

1. Andral P. Cliniques, Paris 1834;2:201.

2. Morton CB. Syphilis of the stomach: review of the literature and report of a case. Arch Surg (Chicago) 1932; 25: 880-9.

3. Palmer WL, Schindler R, Templeton FE, Humphreys EH. Syphilis of the stomach. A case report. Ann Intern Med 1943; 18:393-406.

4. Knight WA, Falk A. Tertiary gastric syphilis. Gastroenterology 1947;9:17-27.

5. Patterson CO, Rouse MO. Description of gastroscopic appearance of luetic gastric lesions in late acquired syphilis. Gastroenterology 1948; 10:474-85.

6. Fancher PS. Syphilis of the stomach. Arch Intern Med 1951; 35:240-8.

7. Cooley RN, Childers JH. Acquired syphilis of the stomach. Report of two cases. Gastroenterology 1960;39:201-7.

8. Madding GF, Baer LS, Kennedy PA. Gastric syphilis. A case report. Ann Surg 1964; 159:271-4.

9. Brochus HL, ed. Gastroenterology. Philadelphia, London, Toronto: WB Saunders, 1974

10. Victor M, Adams RD, Collins GH. The Wernicke-Korsakoff Syndrome. Philadelphia: F A Davis Co, 1971.

11. Moore AB, Aurelius JR. Roentgenological manifestations in eighty-seven cases of gastric syphilis. Am J Roentgenol 1928; 19:425-32. 